\title{
Erratum to: Difficult Decisions in Colorectal Surgery
}

\author{
Neil Hyman and Konstantin Umanskiy
}

\section{Erratum to:}

N. Hyman, K. Umanskiy (eds.), Difficult Decisions in Colorectal Surgery, Difficult Decisions in Surgery: An Evidence-Based Approach, DOI 10.1007/978-3-319-40223-9

In the original version of chapters $24,29,37$ the co-author names and their affiliations were missing. The names of the author should be read:

Chapter 24: Management of the Abnormal Pap Smear in HIV Positive Patients Brad Champagne and Andrew J. Russ

Chapter 29: Who Needs Elective Surgery for Recurrent Diverticulitis?

Janice Rafferty and Bobby Lynn Johnson III

Chapter 37: Which Patients with Fecal Incontinence Require Physiologic Workup? Tracy Hull and Nouf Y. Akeel

The above mentioned corrections are updated in Table of Contents. Also, the affiliations of the co-authors are updated in the respective chapter opening pages.

The updated online versions of these chapters can be found at

DOI 10.1007/978-3-319-40223-9_24

DOI 10.1007/978-3-319-40223-9_29

DOI 10.1007/978-3-319-40223-9_37 